\title{
O Corpo Social do Sujeito ${ }^{1}$
}

Xavier Guchet ${ }^{2}$

Universidade Paris I

\section{Resumo}

Simondon situou o conjunto de seus trabalhos sob o signo de uma confrontação entre a filosofia e as ciências humanas. Partindo da constatação de que as ciências humanas de sua época são insuficientemente unificadas e que elas perdem a realidade do homem concreto e completo, ele quer propor uma filosofia da individuação humana que possa renovar os saberes sobre o homem. Esta filosofia da individuação se apresenta como um esforço para casar estreitamente duas dimensões da realidade humana que são habitualmente tratadas separadamente: as formas de organização social de um lado, os modos de confrontação à matéria do outro. Em suma, o social e o técnico. $\mathrm{Na}$ capacidade de pensar conjuntamente estas duas dimensões, do social e do técnico, lança-se, segundo Simondon, a possibilidade de propor um novo humanismo à altura dos desafios contemporâneos.

Palavras-chave: Simondon; Ciências humanas; Filosofia.

\section{Résumé}

Simondon a placé l'ensemble de ses travaux sous le signe d'une confrontation entre la philosophie et les sciences humaines. Partant du constat que les sciences humaines de son époque sont insuffisamment unifiées et qu'elles manquent la réalité de l'homme concret et complet, il veut proposer une philosophie de l'individuation humaine qui puisse renouveler les savoirs sur l'homme. Cette philosophie de l'individuation se présente comme un effort pour coupler étroitement deux dimensions de la réalité humaine qui sont habituellement traitées séparément: les formes d'organisation sociale d'un côté, les modes de confrontation à la matière de l'autre. Bref, le social et le technique. Dans la capacité à penser ensemble ces deux dimensions du social et du technique, se joue selon Simondon la possibilité de proposer un nouvel humanisme à la mesure des défis contemporains.

Mots-clés: Simondon; Sciences humaines; Philosophie.

\footnotetext{
${ }^{1}$ O presente artigo foi publicado originalmente nos Cahiers Simondon, No. 3 (2011: 71-94), sob a responsabilidade editorial de Jean-Hugue Barthélémy. Agradecemos tanto a Xavier Guchet quanto a Jean-Hugues Barthélémy pela amabilidade em nos permitir sua tradução e publicação.

${ }^{2}$ Tradução de Marcos Nalli, José Fernandes Weber e Américo Grisotto.
}

Filosofia e Educação - ISSN 1984-9605

Volume 6, Número 3 - Outubro de 2014 


\section{Introdução: "Axiomatizar" as ciências humanas}

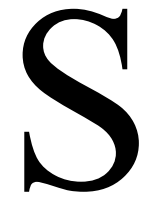

imondon publicou em sua vida dois livros maiores, a partir respectivamente de sua tese principal e de sua tese complementar.

A tese complementar sobre o modo de existência dos objetos técnicos foi publicada em 1958 (2012); entretanto, foi preciso esperar $1964^{3}$ (2005) para que a tese principal sobre a individuação fosse levada ao conhecimento do público (somente uma parte da tese principal: só os capítulos consagrados aos regimes de individuação física e vital foram retidos pelo editor, permanecendo incompletos pela exclusão dos capítulos consagrados à individuação psíquica e coletiva). Em seguida Simondon redigiu textos maiores, mas sob a forma de cursos não publicados, ou então de conferências publicadas em revistas pouco difundidas - pensa-se na notável série de três conferências sobre a psicossociologia da tecnicidade, pronunciadas em Lyon em 1960 e 1961, publicadas no Boletim da Escola Prática de Psicologia e de Pedagogia de Lyon, e que foram reeditadas (2014). É necessário constatar, por conseguinte, que até muito recentemente, os leitores de Simondon tiveram acesso a uma parte limitada da obra - as duas teses essencialmente amputadas das reflexões sobre o regime psicossocial da individuação. Esta situação pode explicar a maneira como Simondon foi lido pelos filósofos: de um lado, como um pensador que propôs uma aproximação original da técnica - original, mas desconcertante (seu curso sobre a invenção e o desenvolvimento das técnicas agregadoras em 1968 suscitou uma certa perplexidade entre os estudantes...); em seguida, como um pensador que propôs uma crítica da metafísica e um novo conceito de indivíduo. Lê-se Simondon com um pensador da técnica (Marcuse, 1968; Naville, 1963), mas também com o autor de uma ontologia

\footnotetext{
${ }^{3}$ Disponível ademais in extenso, Simondon G., L'Individuation à la lumière des notions de forme et d'information [A individuação à luz das noções de forma e de informação], Grenoble, Jérôme Millon, 2005.
}

Filosofia e Educação - ISSN 1984-9605

Volume 6, Número 3 - Outubro de 2014 
do indivíduo (como o faz Deleuze notadamente). Alguns se voltaram, com efeito, ao problema da unidade das duas teses, sobre a questão de saber porque Simondon, nos anos da década de 50, consagrou seus esforços a essas duas espécies de pesquisas à primeira vista tão distantes entre si, sobre o objeto técnico e mais precisamente sobre a máquina industrial de um lado, sobre a metafísica do indivíduo do outro. É preciso compreender que a redefinição do indivíduo é uma passagem obrigatória para falar da máquina? É preciso compreender que a filosofia da técnica é uma simples ilustração da filosofia geral sobre o indivíduo? Convém recusar de privilegiar uma das duas teses em relação à outra? Em todo caso, muito raros são aqueles que tentam interpretar o conjunto da obra de Simondon do ponto de vista de uma confrontação entre filosofia e ciências humanas ${ }^{4}$.

A reflexão sobre as ciências humanas não é, no entanto, um rincão menor da filosofia de Simondon, pode-se mesmo sustentar que ela constitui o fio condutor. Simondon atribui em todo caso uma importância considerável no texto de uma conferência que ele pronunciou na Sociedade Francesa de Filosofia, no mês de fevereiro de 1960 (Simondon, 2005 , p. 531-551): aos ouvintes presentes, que contam entre os representantes mais eminentes da filosofia francesa do momento, substancialmente ele explica o que o levou a empreender suas pesquisas nos domínios da ontologia e da tecnologia, é a constatação de uma falta de "axiomatização" das ciências humanas e a necessidade de remediar essa lacuna. Simondon não dá, é verdade, muitos detalhes sobre o que pode querer dizer aqui "axiomatização". Ele precisa simplesmente que esta situação desagradável

${ }^{4}$ Citemos ao menos Moutaux J., Sur la philosophie de la nature et la philosophie de la technique de Gilbert Simondon [Sobre a filosofia da natureza e a filosofia da técnica de Gilbert Simondon], in Philosophies de la nature [Filosofias da natureza], sob a direção de O. Bloch, Paris, Publications de la Sorbonne, 1994.

${ }^{5}$ Forme, information, potentiel [Forma, informação, potencial], in L'Individuation à la lumière des notions de forme et d'information [A individuação à luz das noções de forma e de informação].

Filosofia e Educação - ISSN 1984-9605

Volume 6, Número 3 - Outubro de 2014 
afetou, e continua a afetar, as relações entre a psicologia e a sociologia e que "axiomatizar" as ciências humanas significa antes de qualquer coisa redefinir as relações entre a psicologia e a sociologia. Esta tarefa aparentemente crucial e urgente exige, sugere Simondon de maneira muito alusiva, ao mesmo tempo uma filosofia do objeto técnico e uma refundação de conceitos como forma, informação, potencial - os quais são precisamente os conceitos maiores de sua filosofia do indivíduo.

Essa conferência é a ocasião para Simondon, que é ainda um jovem filósofo (ele tem 36 anos, em vias de defender suas teses, e não é ainda professor na Sorbonne), de se fazer reconhecer por seus pares, apresentando-lhes a intenção geral de seus trabalhos. Ora, ele escolheu priorizar o problema que toca as ciências humanas, e em particular à psicologia e à sociologia. Este problema, seguramente, está no centro dos debates filosóficos da época, o estruturalismo é então muito discutido: Simondon parece querer oferecer uma contribuição original a esses debates.

Um primeiro ponto merece explicação: por que esta atenção muito particular, para não dizer exclusiva, à psicologia e à sociologia, que nada são, de antemão, senão duas ciências humanas dentre um grande número de outras - a história, a linguística, etc. - de que Simondon não fala por assim dizer? Em que uma requalificação das relações entre psicologia e sociologia é de natureza a resolver o problema de conjunto das ciências humanas e de sua falta de "axiomatização"?

Fato é que a psicologia e a sociologia não são ciências humanas como as outras: suas trocas recíprocas têm poderosamente contribuído para fazer emergir o conjunto das ciências humanas como um novo campo de saber no século dezenove, e constituíram de algum modo em sua polaridade mesma o a priori das ciências nascentes. Esse ato de nascimento deve ser procurado em uma formulação inédita do tema antropológico. Esse tema 
não gira mais em torno da questão, no homem, das relações entre o físico e o moral (o que ainda era o caso no século precedente); ele se volta ademais sobre a questão, nova, das relações entre o físico e o psicológico de um lado, e do social do outro. O homem interior, o homem exterior: tal é a grande polaridade segundo a qual o tema antropológico se encontra reformulado. $\mathrm{O}$ homem é então concebido como um vivente particularmente instável, influenciável por toda sorte de fatores, tanto biológicos quanto sociais. Esta situação pode desembocar sobre os comportamentos patológicos. Trata-se por conseguinte de opor à influenciabilidade e à modificabilidade humanas uma resposta em termos de normas e de regulação das condutas: as normas devem ser postas a fim de que a variabilidade dos comportamentos seja contida em certos limites. Para além desses limites, os comportamentos são julgados patológicos. Influenciabilidade - modificabilidade - resposta normativa: tal é o a priori constitutivo das ciências humanas (Le Blanc, 2005).

Ora, Simondon busca precisamente desfazer em seus fundamentos este a priori das ciências humanas e propõe organizar as trocas da psicologia e da sociologia segundo outra polaridade que aquela do homem interior e do homem exterior. Resumindo excessivamente, sem dúvida, a posição de Simondon sobre este ponto é o seguinte: a realidade humana não se resolve em um problema de articulação da existência psicológica e da existência social, não é jamais partindo como um ser puramente psicológico que o homem encontra, num golpe, o social (senão em casos extremos e patológicos). Como diz Simondon (2005, p. 295), de uma maneira enigmática que será preciso comentar, “o indivíduo só entra em relação com o social através do social". Em outros termos, as ciências humanas são insuficientemente "axiomatizadas" na medida em que a psicologia e a sociologia se dão por objetos as abstrações: o psicológico cortado do social

Filosofia e Educação - ISSN 1984-9605

Volume 6, Número 3-Outubro de 2014 
é uma abstração e reciprocamente. "Axiomatizar" as ciências humanas não significa então, no espírito de Simondon, impor a essas ciências um formalismo comum, isto não é um problema de epistemologia das ciências humanas (não se vê alhures em que este problema seria aquele do filósofo: as ciências humanas são perfeitamente capazes de fazer elas mesmas sua própria epistemologia). Trata-se antes de pontuar o preconceito filosófico que tem sustentado o desenvolvimento das ciências humanas - preconceito constitutivo do a priori das ciências humanas e levando para o objeto dessas ciências, a saber: o homem como duplo interior-exterior, tratado segundo a polaridade do normal e do patológico - e de mostrar em que este preconceito desembocou em uma maneira inadequada, abstrata de falar do homem. "Axiomatizar" as ciências humanas quer dizer, portanto, substituir essas abstrações por uma filosofia da realidade humana concreta, isto é, na linguagem de Simondon: uma filosofia da individuação humana.

É verdade que na época em que Simondon elabora seu próprio pensamento (nos anos 50), a psicologia e a sociologia não estão mais, sem dúvida, a defenderem zelosamente suas fronteiras - alhures elas provavelmente jamais consideraram seus domínios respectivos como fortalezas a proteger. A expressão de Simondon: "é difícil considerar o social e o individual como se enfrentando diretamente em uma relação do indivíduo ante a sociedade" conviria perfeitamente a Durkheim (cf. Karsenti, 2006). No século XX se desenvolvem de, qualquer modo, numerosas correntes na psicologia social que buscam descrever o homem de outro modo que como um misto entre o psicológico e o social. Consequentemente, quando Simondon se atém sobre esse psicologismo e esse sociologismo acusados de tornar as fronteiras totalmente rígidas e impermeáveis, parece lançar um combate de retaguarda; um combate sem objeto. Ele conhecia muito bem esses trabalhos em psicologia social e em 
antropologia cultural, no entanto esses trabalhos não satisfazem, segundo ele, a exigência de "axiomatização" que ele apresenta como fio condutor de suas pesquisas. A constatação pode se resumir da seguinte forma: a psicologia social e a antropologia cultural combinam as análises psicológicas e as análises sociológicas, mas elas não advêm finalmente de uma concepção subjacente do homem como duplo psicossocial. "Axiomatizar" as ciências humanas toma então um sentido original e preciso em Simondon: trata-se de desfazer em seus fundamentos o que Foucault (1966) chamou "o prejuízo antropológico" e se desprender das duas polaridades segundo as quais este tema foi formulado: a polaridade do homem interior e a do homem exterior; a polaridade do normal e do patológico. Não há homem interior e homem exterior; quanto à finalidade de uma sociedade humana, ela não é de manter um estado de equilíbrio, definido por um sistema de normas dadas, contra as variações patológicas que podem ameaçá-la; é de suscitar a invenção, a criação de normas novas. É discutindo a cibernética que Simondon considera a tarefa de propor uma concepção da realidade humana como alternativa ao "prejuízo antropológico". Com efeito, ele consagra dois notáveis textos à cibernética no início dos anos 50 (estes textos ainda são inéditos), em uma época em que a jovem ciência dos "mecanismos teleológicos" interessa bem pouco aos filósofos franceses (com raras exceções, como Georges Canguilhem ou Raymond Ruyer, notadamente). O cerne da crítica de Simondon é a seguinte: a cibernética está errada por querer a qualquer custo tratar as sociedades humanas segundo modelos homeostáticos. Ele está, sobre este ponto, muito próximo da crítica que Canguilhem faz da cibernética por ocasião de uma conferência pronunciada em 1955 sobre "O problema das regulações no organismo e na sociedade" (Canguilhem, 2002). Discutindo a ideia do biólogo Walter Cannon, proposta no início dos anos 30, de aplicar o 
conceito de homeostase às sociedades humanas, Canguilhem observa que as normas não funcionam nas sociedades humanas como nos organismos: enquanto a norma vital é dada com o funcionamento do organismo, a norma social jamais é dada e deve ser construída, quer dizer, discutida. Ela é assunto de política e não de medicina ou de profilaxia social. A finalidade de uma sociedade humana não é de manter equilíbrios. Canguilhem, assim como Simondon, recupera, por conseguinte, o Bergson de Les deux sources de la morale et de la religion [As duas fontes da moral e da religião] (1982): as morais e as religiões "fechadas" são sem dúvida morais e religiões conservadoras, que têm por função preservar a estabilidade da ordem social existente; mas elas não são respectivamente, nem toda moral e nem toda religião: as morais e as religiões "abertas" têm, ao contrário, por função mergulhar novamente as sociedades humanas no élan de criação que lhes marcou, e de lhes permitir se desprender da ordem existente, de inventar o novo, de se tornar outra coisa.

Convém, por conseguinte, precisar qual é a concepção da realidade humana, isto é, da individuação humana, que Simondon crê substituir o “prejuízo antropológico". Para isso, convém se deter sobre algumas páginas dos capítulos da tese principal consagradas à individuação psicossocial. Com efeito é aqui, nesses capítulos todavia negligenciados (e muito curiosamente) pelo editor da tese principal em 1964, que se encontram os elementos principais dessa "axiomatização" das ciências humanas de que Simondon fala.

\section{Da psicologia social à ontologia do coletivo}

É preciso admitir que abordar a questão da individuação humana a partir do psicossocial não é óbvia. De fato, Simondon observa muitas vezes que uma filosofia da realidade humana concreta não pode começar por apartar o

Filosofia e Educação - ISSN 1984-9605

Volume 6, Número 3 - Outubro de 2014 
homem do vital. É por outro lado o que motiva sua rejeição do que se chama "a antropologia". Ele não visava, bem entendido, com este termo, os saberes antropológicos do qual ele se nutriu (pensa-se em particular no estudioso da pré-história André Leroi-Gourhan, que Simondon tanto estimava); ele se prende antes a uma doutrina que é "obrigada a substancializar seja o individual seja o social para dar uma essência do homem".

Por isso, a noção de antropologia comporta já a afirmação implícita da especificidade do Homem, separado do vital. Ora, é deveras correto que não se pode fazer derivar o homem do vital, se subtrairmos do vital o Homem; mas o vital é o vital comportando o homem, não o vital sem o Homem; é do vital até o Homem e compreendendo o Homem; há o vital inteiro, incluso o Homem (Simondon, 2005, p. 297).

Quando da conferência na Sociedade Francesa de Filosofia, em fevereiro de 1960, Simondon responde a questão de um ouvinte explicando que uma antropologia lhe parecia impossível. Em outros termos, não há antropologia: só há biologia, no sentido de uma biologia alargada que compreende o Homem. Propor uma filosofia da realidade humana concreta é, pois, começar pelo vital e não pelo psicossocial. Começar pelo psicossocial não é se arriscar alocar a realidade humana em uma abstração desconectada do vital?

Para responder a esta objeção, é possível aqui lembrar que Simondon foi aluno de Canguilhem, e que para Canguilhem o homem é justamente o vivente pelo qual as normas sociais transformam até o significado das normas biológicas. Nesta perspectiva, começar pelo psicossocial não é supor o Homem desatado do vital; ao contrário, é 
procurar compreender como, no caso do homem, a individuação psíquica e coletiva reorganiza até os alicerces da individuação vital.

Temos aqui uma primeira percepção detida dos termos em que se põe o problema, crucial para os comentadores, das relações entre individuação humana e individuação das técnicas - quer dizer das ligações entre as duas teses defendidas por Simondon em 1958. Deve-se reter dois pontos: 1) uma antropologia do Homem apartado do vital é impossível; 2) o homem é o ser que faz com que as normas de sua existência coletiva reajam sobre as normas de sua vida biológica. A conclusão se impõe obviamente: não há nenhum sentido em rejeitar as intervenções técnicas sobre o homem pelo motivo que elas podem alterar sua biologia (pensemos aqui nos debates atuais sobre as biotecnologias e as nanotecnologias). Do ponto de vista de Canguilhem e Simondon, tal julgamento não pode ter sentido. Provavelmente isto quer dizer que não há limites para nossas intervenções biotécnicas sobre os seres vivos e em particular sobre o vivente humano? Obviamente não é esta a conclusão a que chega Simondon. A filosofia da individuação humana de Simondon nos dota, ao contrário, da capacidade de formular julgamentos de valor sobre as biotécnicas. Dizer que não há essência do homem não implica que no domínio das intervenções biotécnicas tudo é possível e tudo é permitido. Entre a invocação de uma "natureza humana" e o "vale tudo", Simondon empreende uma difícil, mas também necessária, terceira via, que é preciso agora seguir examinando a forma que Simondon solidariza o problema da existência para muitos (o psicossocial) e o problema dos modos de confrontação à matéria (a técnica), para além do caso particular em que a intervenção técnica recai diretamente sobre o homem mesmo - caso que Simondon permanentemente evocou, mas de forma marginal.

\begin{tabular}{c}
\hline Filosofia e Educação - ISSN 1984-9605 \\
Volume 6, Número 3 - Outubro de 2014
\end{tabular}


Segundo Simondon, o erro das diferentes correntes da psicossociologia existente é que elas permanecem tributárias de um gravíssimo pressuposto da metafísica clássica, que Simondon expõe desde as primeiras páginas de sua tese principal. Esse pressuposto é o seguinte: a única realidade ontologicamente consistente é aquela do ser individuado e é ela que urge explicar; a operação de individuação mesma não tem “classificação de ser”, ela não tem consistência ontológica. Toda ciência é assim ciência de estruturas constituídas, quer dizer de estruturas vazias de toda referência às suas operações construtivas. Nas ciências humanas, esse pressuposto metafísico se traduz por uma separação dos domínios científicos e pela institucionalização das disciplinas separadas - a psicologia, a sociologia - deixando para depois que uma certa porosidade entre esses domínios seja reconhecida e que as circulações entre as disciplinas sejam julgadas possíveis. É nisto que chegou a psicologia e a sociologia: todas as duas se desenvolveram como ciências de realidades já individuadas, já estruturadas - a realidade física, a realidade social - ainda que de uma a outra, admite-se por muito tempo (desde sempre sem dúvida) a necessidade de intercâmbios frutíferos. Nessa perspectiva metafísica que continua a ser aquela da psicossociologia da época (segundo Simondon), a relação é posterior aos seres que ela religa, ela não tem qualquer realidade própria. A existência psicossocial é desse ponto de vista interpretável como uma relação entre dois domínios pré-constituídos: o psíquico e o coletivo. Por consequência, no fundamento da operação de individuação, a metafísica clássica está obrigada a procurar alguma coisa que já é um ser individuado e que se supõe que detém o "princípio de individuação" (é o caso, por exemplo, de uma estrutura psíquica ou de uma estrutura social determinada). Para explicar uma gênese de individualidade, ela já se dá um indivíduo: ela pressupõe assim o que está em questão. Simondon então 
pergunta: como evitar esta petição de princípio? É preciso partir de uma situação em que a individualidade não seja pressuposta de maneira alguma. É então pela própria operação de individuação que é preciso se interessar, estabelecendo uma concordância entre a "classe de ser" e a relação: para explicar a gênese de individualidade, é preciso partir da existência de um sistema segundo diferentes "fases" complementares. O ser individuado não é a única realidade após a operação de individuação: ele só é uma das "fases" do ser, apelando como complementar para uma realidade não individuada. Essa descrição não é surpreendente em biologia: sabemos bem que um ser vivo não existe como ser individuado à parte do meio ambiente, para entrar depois em relação com meio já constituído; a individuação do ser vivo e a constituição do meio são contemporâneos e complementares. Simondon eleva essa concepção da individualidade biológica (que é muito claramente enunciada por Canguilhem) ao nível de uma filosofia geral da ontogênese definida como "teoria das fases do ser". Simondon apresenta aqui os principais conceitos e o método de seu programa de "axiomatização" da psicologia e da sociologia: considerar o psicológico e o social como duas "fases" da individualidade humana, a partir de um processo de "defasagem" no interior de um sistema de realidade préindividual rica em potenciais.

Esse sistema de realidade pré-individual não pressupõe nem o psíquico e nem o coletivo: trata-se do sistema de realidade constituída pela individuação vital. A individuação do vivente não esgota todas as tensões e todos os potenciais contidos na situação pré-vital; o par vivente/meio, ponto final de uma "defasagem" imprevista num sistema de ser físico-químico, deixa potenciais não utilizados. Em outros termos, o vivente humano é esse vivente muito particular que não pôde resolve suas problemáticas vitais no interior da ordem vital: ele só pôde encontrar soluções a seus problemas de

Filosofia e Educação - ISSN 1984-9605

Volume 6, Número 3-Outubro de 2014 
adaptação tornando-se outra coisa que um "simples vivente", como diz Simondon. Pode-se pensar aqui nas análises de Leroi-Gourhan sobre o equilíbrio do físico e do psíquico no homem, implicando a exteriorização das funções biológicas nos utensílios e nas máquinas, implicando também a exteriorização das programações do vivente numa memória social. O gesto e a palavra - para retomar o título da obra maior de Leroi-Gourhan (1964 e 1965 ) - constituem as duas "fases" da hominização, quer dizer, da resposta especificamente humana para uma problemática vital, supondo a entrada num novo regime de individuação acima da "simples" vida. Esta análise e esta aproximação com Leroi-Gourhan permite encontrar um certo número de pré-requisitos do pensamento da individuação humana: primeiramente, a recusa em separar o homem do vital; em segundo, a recusa de considerar o homem como um duplo psicossocial; terceiro, a ideia que, resolvendo suas problemáticas vitais, passando a um regime de individuação superior à vida, o homem mudou a significação mesma de seu "viver". Ser homem é fazer sair o psicossocial do vital - não como um efeito de sua causa, mas como uma solução de um problema - e, em retorno, fazer reagir a existência psicossocial sobre a significação mesma da existência biológica.

\section{O sujeito como operação}

É sem dúvida nos capítulos da tese principal - Problemática da ontogênese e individuação psíquica e $O$ individual e o social, a individuação do grupo - que Simondon (2005, p. 263-306) precisa melhor sua concepção da individuação humana. Simondon põe nessas páginas a questão da gênese do sujeito individuado. Ele começa por estabelecer que a dúvida cartesiana não dá conta dessa gênese. Ele pressupõe o contrário: com efeito, se Descartes pôde pretender que a dúvida desse conta da gênese do Cogito, é confundindo dois sentidos da dúvida: há de uma parte a "dúvida duvidante",

Filosofia e Educação - ISSN 1984-9605

Volume 6, Número 3 - Outubro de 2014 
a operação mesma da dúvida, e há por outra parte a "dúvida duvidada", o objeto da dúvida. Descartes quis que na operação mesma da dúvida o sujeito se tomasse como objeto da dúvida; o sujeito tomando-se como sujeito duvidante, a operação se objetiva no momento mesmo em que ela se exerce. O "duvidante" e o "duvidado" coincidem. Ora, o que Descartes negligencia é precisamente a distância que jamais pode ser coberta entre a operação de duvidar e o objeto da dúvida, entre o "duvidante" e o "duvidado": eu duvido de mim mesmo no ato de duvidar, mas no instante mesmo em que creio ter nas mãos a operação de duvidar para fazê-la um objeto da dúvida, ela me escapa como operação. A dúvida objetivada é uma dúvida superada, a atualidade da operação da dúvida escapa à objetivação.

A dúvida é dúvida sujeito, dúvida operação em primeira pessoa e também dúvida que se destaca da operação de duvidar atual como dúvida duvidada, operação completamente já objetivada [...] Entre a dúvida duvidante e a dúvida duvidada se constitui certa relação de distanciamento através da qual, no entanto, se mantém a continuidade da operação (Simondon, 2005, p. 285).

Se é impossível apoiar a gênese do sujeito, é que precisamente o sujeito é essa separação, essa "relação de distanciamento", essa "tomada de distância" que é ao mesmo tempo "ligação". Descartes pensou poder tomar a gênese do Cogito porque ele compreendeu o Cogito como uma estrutura, como uma substância, "como res e como cogitans, suporte de operação e operação em vias de se preencher" (Simondon, 2005, p. 286): ora, o sujeito não é substância e não é estrutura, ele é a realidade de uma operação inassimilável às estruturas constituídas. Simondon chama "memória" essa tomada de distância sem alienação. Ele é aqui, há de se admitir, muito 
bergsoniano. O erro de Descartes é de ter suposto uma relação simétrica entre o "duvidante" e o "duvidado": na objetivação do "duvidado", o "duvidante" se toma efetivamente como "duvidante" posto que "duvidante" e "duvidado" têm a mesma estrutura, têm o mesmo suporte substancial. Para ser mais preciso, o "duvidante" e o "duvidado" coincidem segundo Descartes porque todos os dois são compreendidos como realidades estruturais, e que a objetivação do "duvidante" em "duvidado" não altera sua comum identidade de estrutura. Desde então, contrariamente ao que se compreende, o sujeito como operação e não como estrutura, é uma relação de assimetria que constitui o sujeito: assimetria entre uma operação presente que sempre se escapa e uma estrutura objetivada que já está sempre no passado. É o estabelecimento de tal reciprocidade assimétrica entre estruturas e operações no ser que Simondon chama uma individuação. A partir de então, “o progresso da memória é um desdobramento assimétrico do ser sujeito, uma individualização do ser sujeito" (Simondon, 2005, p. 285). A operação cria uma assimetria entre o presente e o passado, ela constitui o passado como passado: o passado é o campo reticulado, é uma primeira aproximação como o cristal já formado na água-mãe. O presente seria antes como o limite do cristal em formação, propagando e prolongando a operação de tomar forma. Seguramente isto é apenas uma aproximação na medida em que o passado do sujeito não um resíduo morto e completamente inerte (o que é o caso do cristal): como bem sabemos, nossa capacidade atual para individuar e para nos individuar é rica de todo nosso passado; nosso passado permanece informador de nosso presente.

O passado é então o que Simondon chama um "símbolo" do eu, quer dizer a realidade complementar do eu atual. O sujeito é mais que o eu atual; o eu atual e o passado são duas "fases" complementares do sujeito. $\mathrm{Na}$

Filosofia e Educação - ISSN 1984-9605

Volume 6, Número 3 - Outubro de 2014 
operação da memória, o passado é o indivíduo, o estruturado; o eu atual é como o meio, é uma reserva de potenciais.

Simondon desenvolve uma análise análoga tocando a assimetria do presente e do futuro, assimetria que se constitui não mais na operação de memória, mas naquela da imaginação. A diferença dos dois, memória e imaginação, reside em uma espécie de quiasma: enquanto na memória o “símbolo" do eu (o passado) é o indivíduo, na imaginação é o eu atual que é o indivíduo: o futuro é o campo de potenciais, zona de realidade não individuada, meio ambiente. $\mathrm{O}$ eu atual é então ao mesmo tempo indivíduo e meio, indivíduo em relação ao porvir, meio em relação ao passado. O presente do eu é então definido como "transdução entre o campo do porvir e os pontos em rede do passado" (Simondon, 2005, p. 288).

Ora, “o produto dessa individuação psíquica, diz Simondon (2005, p. 287), só é de fato psíquico no centro; o psíquico puro é o atual; o passado tornado passado longínquo e o futuro distante são realidades que tendem para o somático". O passado e o futuro se incorporam. A consciência se liga ao corpo pela memória e pela imaginação. A alma pura e o corpo puro, a res cogitans e a res extensa cartesianas, são dois casos extremos, duas abstrações prévias sobre um contínuo psicofísico constituído pela transdutividade de uma operação. Por transdutividade, Simondon entende precisamente a conservação e a propagação, não de uma estrutura constituída que se mantém idêntica a si mesma (a identidade a da substância cartesiana), mas aquela de uma operação criadora da assimetria e das complementaridades de "fases" em um sistema de realidade rico em potenciais. O que define a identidade do sujeito, não é a performance de uma estrutura, é a permanência dessa operação que estrutura um campo de potenciais (o futuro) em uma rede de pontos-chaves (o passado).

Filosofia e Educação - ISSN 1984-9605

Volume 6, Número 3 - Outubro de 2014 
Passado e futuro são então o não-presente, o inatual, e o corpo é "passado e futuro puros". A alma está no corpo como o presente está entre o futuro e o passado. A alma é transdução entre duas corporeidades, aquela do futuro, que é o campo de virtualidades, e aquela do passado, que é rede de pontos-chaves. Há então uma espécie de dupla natureza do corpo: o corpo é meio para o eu presente que aí busca virtualidades, tensões, porvir; mas ele é também indivíduo para o eu presente que o vive como o que carrega todo o peso das estruturas impostas do socius. Para Simondon, é definitivamente pelo corpo que eu me vinculo ao coletivo.

\section{A individuação transindividual e os dois sentidos do social}

$\mathrm{Na}$ interpretação anti-substancialista de Simondon, o problema da integração social do indivíduo não pode ser colocado em termos de enfrentamento direto entre um indivíduo já constituído e uma socialmente igualmente constituída. Isto implicaria em reintroduzir o prejuízo da metafísica clássica, estipulando que toda realidade só pode se explicar por referência a estruturas pré-existentes (aqui, o indivíduo e a sociedade), as operações sem ter "razão de ser", quer dizer sem consistência ontológica. O problema da integração social do indivíduo é também um problema de operações e não um problema de relação entre estruturas dadas. A integração social é uma individuação, um processo; os termos da relação (indivíduo e sociedade) aparecem por "defasagem" e são derivados da relação mesma. É preciso definir um novo regime de individuação segundo o qual o indivíduo se constitui simultaneamente ao coletivo; quer dizer, um regime de individuação que torna compatíveis e complementares o que Simondon chama "a individuação pessoal" e "a individuação social". Pressupor a compatibilidade entre a dimensão de relação a si (a individuação pessoal) e a dimensão de relação aos outros seres individuados

Filosofia e Educação - ISSN 1984-9605

Volume 6, Número 3 - Outubro de 2014 
(individuação social), é cometer uma petição de princípio posto que o problema da individuação humana reside inteiramente no estabelecimento dessa compatibilidade. Ora, justamente, esta compatibilidade não está de modo algum garantida. Com efeito, a individuação pessoal e a individuação social parecem caminhar a reboque uma da outra: a sociedade exige dos seres individuados que eles se integrem à ordem estabelecida, isto é, que eles construam seu futuro segundo as normas herdadas do passado: a sociedade exige de cada um que endosse os papéis sociais bem definidos, e que faça seus um certo número de fins impostos.

O indivíduo se vê a propor fins, papéis a escolher; ele deve tender para esses papéis, para os tipos, para as imagens, ser guiado por estruturas que ele se esforça por realizar concordando com elas e complementando-as: a sociedade diante do ser individual apresenta uma rede de estados e papéis através dos quais a conduta individual deve passar (Simondon, 2005, p. 293).

O ser individuado é, por conseguinte, incitado a forjar seu futuro segundo uma rede de pontos-chaves que define o passado de uma sociedade. O futuro do sujeito, é o passado da sociedade. Tal é a tensão de partida, a incompatibilidade entre individuação pessoal e a individuação social. Como sempre em Simondon, uma incompatibilidade clama por uma estratégia de resolução de problema, que passa na ocorrência pela entrada dos seres individuados em um regime de individuação inédita; um regime de individuação que compatibiliza a individuação pessoal e a individuação social. É esse regime de individuação que Simondon chama de "transindividual”. "A integração do indivíduo ao social se faz pela criação de uma analogia de funcionamento entre a operação que define a presença 
individual e a operação que define a presença social; o indivíduo deve encontrar uma individuação social que recubra sua individuação pessoal" (Simondon, 2005, p. 295). Retomando a terminologia da psicologia social norte-americana, Simondon chama in-group essa dimensão coletiva da personalidade individual. O in-group (ou transindividual) não é "uma realidade substancial que deveria ser superposta aos seres individuais e concebida como independente deles: é a operação e a condição de operação pela qual se cria um modo de presença mais complexa que a presença do ser unicamente individual". "A relação entre o indivíduo e o transindividual se define como o que supera o indivíduo todo, prolongando-o: o transindividual não é o exterior do indivíduo e, no entanto, se destaca em certa medida do indivíduo". O transindividual ou in-group assume uma dimensão de transcendência em relação à individuação pessoal, mas não se trata de uma estrutura transcendente aos indivíduos: é antes de uma alteração interna dos indivíduos, de uma dimensão de transcendência dos indivíduos que "enraíza na interioridade", que "não carrega uma dimensão de exterioridade mas de superação em relação ao indivíduo". Seguindo Merleau-Ponty (1988), Simondon quer pensar a existência para muitos como uma transcendência do indivíduo (e não para o indivíduo), uma transcendência de dentro, sugerindo que o indivíduo não está encerrado em seus próprios limites, sem no entanto que isso implique a suposição de uma positividade transcendente, de uma sociedade pré-existente e evidente.

Essa dimensão de transcendência $d o$ indivíduo e não para $o$ indivíduo encontra sua origem na carga de pré-individualidade que permanece sempre atada ao indivíduo. $\mathrm{O}$ transindividual faz comunicar os indivíduos no nível pré-individual que nenhuma individuação esgota completamente, "que é ainda rica em potenciais e em forças organizáveis" 
(Simondon, 2005, p. 166) e que torna possível a entrada de novas individuações.

Pode-se entender [por transindividualidade] uma relação que não põe os indivíduos em relação ao meio de sua individualidade constituída separando-as umas das outras, nem ao meio do que há de idêntico em todo sujeito humano [...] mas o meio dessa carga de realidade pré-individual, dessa carga de natureza que é conservada com o ser individual, e que contém potenciais e virtualidade (Simondon, 2005, p. 248).

Nós podemos nos comunicar com os outros sobre a base das estruturas que estão em nós, por exemplo as estruturas da linguagem ou as normas que o socius nos inculca. Todavia, há uma parte de nós mesmos que não está na estrutura e que nos torna capazes de inventar, de introduzir novidade no mundo (encontra-se aqui a ideia de Canguilhem: a finalidade das sociedades humanas não é o equilíbrio homeostático; é a invenção). A relação transindividual é, portanto,

o que faz que os indivíduos existam juntos como os elementos de um sistema comportando potenciais e metaestabilidade, expectativa e tensão, depois descoberta de uma estrutura e de uma organização funcional que integram e resolvem essa problemática [...] O transindividual passa no indivíduo [relação interna portanto] como do indivíduo ao indivíduo [relação externa] (Simondon, 2005, p. 302).

O psicossocial verdadeiro é o transindividual. A relação transindividual não é "nem de origem social nem de origem individual; ela é depositada no 
indivíduo, levada por ele"; dito de outro modo, ela não é transcendência aos indivíduos, "mas ela não lhe pertence e não deriva de seu sistema de ser como indivíduo [...] O indivíduo conservou consigo o pré-individual, e todos os indivíduos conjuntamente têm assim um tipo de fundo não estruturado a partir do qual uma nova individuação pode se produzir" (Simondon, 2005, p. 303).

A passagem ao transindividual não sobrepõe uma individualização (coletiva) para uma individuação prévia (pessoal); ela vem complicar a individuação pessoal, ela a torna "mais complexa". Em outros termos, a individuação transindividual não cria uma realidade outra que o indivíduo: ela cria uma realidade individual nova, o que é muito diferente. A individuação pessoal implica ademais a relação aos outros. "A interioridade de grupo é uma certa dimensão da personalidade individual, não uma relação de um termo distinto do indivíduo; é uma zona de participação em torno do indivíduo" (Simondon, 2005, p. 295).

O frente-a-frente do in-group, o out-group, designa então essa realidade social parecendo como que uma realidade transcendente, coerciva, impondo aos seres individuados passagens obrigatórias, uma estrutura de ordem herdada do passado, regras codificadas, etc. É porque a ideia que a sociedade é uma realidade exterior e transcendente não é completamente falsa e sem fundamento: uma ontologia do processo não culmina na invalidação pura e simples dessa ideia, ao contrário ela a precisa. O outgroup é, para ser justo, vivido como o social substancializado, mas não é todo o social: a integração ao out-group não implica um indivíduo présocial, ela concerne um ser individuado que já dilatou sua personalidade até aos limites do in-group; a integração social dos indivíduos se faz por mediação do in-group (salvo nos casos extremos e patológicos, como por exemplo os casos de delinquência ou de alienação mental, segundo 
Simondon: nesses casos, todo grupo aparece ao indivíduo como um grupo de exterioridade). É o que queria dizer Simondon ao escrever: "o indivíduo só entra em relação com o social através do social". Compreendamos: o indivíduo só entra em relação com o out-group (primeiro sentido do social) através do in-group (segundo sentido do social).

\section{Corpo e transindividualidade: Simondon e Bergson}

Ora, a criação dessa zona de participação que define um regime de individuação "mais complexa" implica o corpo. "O corpo próprio do indivíduo se estende até os limites do in-group; assim como existe um esquema corporal, existe um esquema social que se estende os limites do eu até à fronteira do in-group e do out-group. Pode-se considerar em um certo sentido o grupo aberto (in-group) como o corpo social do sujeito" (Simondon, 2005, p. 294). O out-group pode também ser qualificado de grande corpo. Inútil lembrar aqui a antiguidade das aproximações entre organismo e sociedade. A conclusão importante a qual conduz a análise de Simondon é que essa tem dois sentidos, conforme se fale do in-group ou do out-group. Lembremos que para Simondon, o corpo é ao mesmo tempo futuro e passado, campo de potencialidades e rede de pontos-chaves. O corpo social-organismo é essa rede de pontos-chaves que me impõe estruturas de ordem; o corpo social no sentido de in-group é esse campo de virtualidades que eu posso tomar para continuar minha individuação pessoal. Essa análise não deixará de evocar coisas que o senso-comum pode experimentar: o corpo não é ao mesmo tempo o que nos socializa na medida em que, desde nossa mais tenra infância, os hábitos (quer dizer, as estruturas estabelecidas) nos são inculcadas? Mas o corpo não é também o que me permite me desprender das estruturas estabelecidas para me tornar outra coisa? Mauss (1950, p. 363-386) tratou muito bem dessa ambivalência do

Filosofia e Educação - ISSN 1984-9605

Volume 6, Número 3 - Outubro de 2014 
corpo em seu famoso artigo sobre as técnicas do corpo. Nos termos de Simondon, o corpo do sujeito se articula ao mesmo tempo sobre o in-group e sobre o out-group. A relação do indivíduo ao

in-group e sua relação ao out-group são um e outro como o futuro e o passado; o in-group é fonte de virtualidades, de tensões, como o futuro individual; ele é reservatório de presença [...] Sob a forma de crença, a pertença ao grupo de interioridade se define como uma tendência não estruturada, comparável ao futuro para o indivíduo: ela se confunde com o futuro individual, mas ela assume também o passado do indivíduo, pois o indivíduo se dá uma origem nesse grupo de interioridade, mítico ou real (Simondon, 2005, p. 295).

É a razão pela qual no in-group, a individuação pessoal e a individuação grupal são compatíveis e complementares; seria necessário mesmo dizer recíprocos; elas caminham lado a lado e não a reboque: o futuro e o passado individual coincidem respectivamente com o futuro e o passado do ingroup. A relação com o out-group ao contrário, é uma relação já constituída: é no passado social que o ser individuado é chamado a atar seu futuro.

Essa filosofia da individuação implica, portanto, uma filosofia do corpo compatível com a ideia de transindividualidade. Como compreender que o corpo próprio possa se estender até os limites do in-group? A resposta reside na constatação de uma enorme dívida que Simondon tem para com Bergson. Em matéria de pensamento social, Simondon evoca Bergson de maneira verdadeiramente crítica: ele lhe reprova a distinção (que julga demasiadamente marcada, substancial demais) entre sociedades fechadas e sociedades abertas: "É vão proceder à maneira de Bergson opondo grupo aberto e grupo fechado; o social, à curta distância, é aberto; de longe, 
fechado" (Simondon, 2005, p. 294). O in-group e o out-group, ou grupo aberto e grupo fechado não se opõem como duas realidades mutuamente exclusivas: a integração social é a integração no out-group, mas essa integração supõe uma dilatação prévia da personalidade individual até os limites de um grupo de pertencimento. Dito isto, independentemente do fato que Bergson sem dúvida alguma opôs tão categoricamente quanto pretende Simondon as sociedades fechadas e as sociedades abertas, é precisamente em Bergson que se encontra essa filosofia do corpo de que Simondon necessita para pensar essa dimensão de transcendência do indivíduo.

Em Les deux sources de la morale et de la religion, Berson escreve o seguinte: nosso corpo "vai até às estrelas". "Mesmo por seu corpo, o homem está longe de só ocupar o mínimo lugar que se lhe atribui ordinariamente [...] Pois se nosso corpo é a matéria pela qual nossa consciência se aplica, ele é coextensivo à nossa consciência, ele compreende tudo o que percebemos, ele vai até às estrelas" (Bergson, 1982, p. 274). Bergson explica que o encarceramento da consciência nesse "corpo mínimo", delimitado pelo invólucro corporal propriamente dito, conduz a negligenciar o "corpo imenso" (isto é, coextensivo a tudo o que nós percebemos), e é o produto de uma ilusão metafísica. Ele precisa também que o "corpo mínimo" não é pura e simplesmente absorvido no "corpo imenso", ele é o ponto a partir do qual o conjunto do grande corpo muda. Esse texto é muito elíptico, Bergson remete a nota de pé de página ao primeiro capítulo de Matière et mémoire [Matéria e memória]. É aí então que é preciso ir buscar as explicações mais detalhadas.

Bergson descreve aí o que chama a "percepção pura", quer dizer uma sorte de ideal de percepção esvaziada de toda referência à memória. Essa percepção não existe, ela seria uma percepção instantânea. Se Bergson se vale dessa abstração, é porque ela apenas lhe permite descrever a 
natureza verdadeira da percepção. Bergson se detém em uma ilusão metafísica que consiste em dizer que as percepções são construções mentais feitas a partir de sensações inextensivas, projetadas fora da consciência. Isso é incompreensível, diz Bergson. Como posso fazer o extenso a partir da inextensão? Como posso fazer a exterioridade a partir da interioridade? Como posso fazer a percepção com as afecções? (eu sou afetado, mas jamais compreenderei que as afecções possam ser convertidas em representações de qualquer coisa externa). Bergson inverte então completamente os termos do problema e propõe compreender o corpo como um objeto material dentre outros, o que ele chama uma imagem. A imagem em Bergson não é uma construção da consciência, ela é o mundo exterior, ela designa o aparecer das coisas quando eu abro os olhos (ou os outros sentidos: há, por exemplo, imagens táteis). Todas essas imagens agem e reagem umas em relação às outras em todas suas partes elementares segundo leis constantes, as leis da natureza. O universo das imagens é determinista. Todavia, entre essas imagens, há uma aí que se destaca: é meu corpo. Meu corpo não é somente percebido, ele é também sentido. Essas afecções vêm se intercalar entre a ação das outras imagens sobre meu corpo, e o movimento que meu corpo reenvia às imagens. Elas introduzem uma parte de indeterminação em minha resposta à ação das coisas sobre mim. Dito de outro modo, as afecções culminam em atos que não podem rigorosamente se deduzir dos fenômenos anteriores, segundo as leis da natureza: eles manifestam a capacidade que tenho de escolher minhas respostas e de introduzir novidades no mundo. "Meu corpo é então, no conjunto do mundo material, uma imagem que age como as outras imagens, recebendo e dando movimento, com apenas uma diferença, talvez, que meu corpo parece escolher" (Bergson, 1965, p. 14). Meu corpo é, por conseguinte, um "centro de ação" e não um produtor de representações do

Filosofia e Educação - ISSN 1984-9605

Volume 6, Número 3-Outubro de 2014 
mundo exterior a partir de sensações inextensivas. Ele recebe movimento e o restitui, com essa diferença em relação às outras imagens, que ele escolhe sua resposta. Ele decide entre muitas abordagens materialmente possíveis. Como ele escolhe? Ele escolhe em função da maior ou menor vantagem que pode tirar das imagens ao seu redor. A partir daí, conclui Bergson, "é necessário que essas imagens assinalem de alguma maneira, na superfície direcionada ao meu corpo, o partido que meu corpo poderá tirar delas" (Bergson, 1965, p. 15). Em outras palavras, os objetos que me cercam são o exato reflexo da ação possível de meu corpo sobre eles: as imagens agem sobre mim, meu corpo reflete a ação que ele virtualmente tem sobre elas. Ei o que é a percepção de uma coisa: a reflexão da ação possível de meu corpo sobre essa coisa. A percepção não é da ordem de uma representação, ela é da ordem da ação: ela é proporcionada pela possibilidade que tenho de agir sobre as coisas. "Nossa representação da matéria é a medida de nossa ação possível sobre os corpos" (Bergson, 1965, p. 35). A percepção limita, corta no tecido do universo: "indefinida de direito, ela se restringe, de fato, a assinalar a parte de indeterminação deixada pelas abordagens dessa imagem especial que chamais vosso corpo" (Bergson, 1965, p. 38). Um organismo de possibilidades de ação muito limitadas terá uma percepção limitada; um organismo cujo sistema nervoso central autoriza uma gama de ações possíveis muito extensa terá uma percepção em relação com essa riqueza: sendo ela também rica. Não há então mais na percepção/representação que na coisa: há menos. Não se compreende totalmente como alguma coisa pode ser acrescida às sensações inextensivas que me afetam para produzir um objeto extenso, tomando lugar no mundo exterior; por outro lado, não há problema para compreender que meu corpo, imagem entre as imagens, seleciona no universo os aspectos das coisas que interessam diretamente à sua ação possível sobre elas: ele deixa de lado o que não interessa a sua

Filosofia e Educação - ISSN 1984-9605

Volume 6, Número 3-Outubro de 2014 
ação. A percepção aparece quando uma ação das coisas sobre o corpo não provoca imediatamente uma resposta automática (se há automatismo, não há nem percepção nem consciência): ela aparece quando há atraso e escolha. A percepção não é então um fenômeno mental, ela se faz nas coisas e por ela nós nos colocamos junto às coisas. Meu corpo, não sendo um centro de representações mas um centro de ação, é coextensivo a suas possibilidades de ações sobre o universo das imagens.

Se se retorna agora ao texto de Les deux sources de la morale et de la religion, vê-se bem que esse corpo desmesuradamente grande de que fala Bergson não é uma metáfora, isso não designa metaforicamente "o corpo social" (no sentido do out-group de Simondon): esse corpo crescido não é outro senão meu corpo, definido como centro de ação. O ponto crucial da análise é que ao definir o corpo como centro de ação, subordinando aí a percepção à ação (é, aliás, o que também fez Simondon), Bergson solidariza de maneira muito estreita o problema da existência para muitos e o problema dos modos de confrontação à matéria. Descobre-se que o modo de agrupamento dos homens não é de todo indiferente aos modos de confrontação à matéria, que abrem para possibilidades de ação marcantes. Em termos simondonianos, uma filosofia da individuação humana implica ter junto o pensamento do transindividual - o "corpo social" do indivíduo e o pensamento da técnica - o tipo aliança do homem e da matéria em um dado momento, em uma sociedade dada. Tem-se aqui, então, a unidade das duas teses.

\section{Conclusão}

Em uma época (os anos cinquenta) em que as diatribes contra o suposto "anti-humanismo" das máquinas industriais constituem praticamente o único discurso filosófico sobre a técnica, Simondon surge como um

Filosofia e Educação - ISSN 1984-9605

Volume 6, Número 3 - Outubro de 2014 
pensador resolutamente iconoclasta. Defendendo a ideia que as máquinas são realidades culturais por inteiro, da mesma forma que as obras de arte, sem dúvida ele surpreendeu. Indo até a tese defendida de que uma filosofia da individuação humana deve pensar o homem sobre a base de seus modos de engajamento na matéria - quer dizer, definitivamente, sobre a base de suas técnicas - ele corre fortemente o risco de permanecer incompreendido na época. No entanto, ele apenas eleva ao plano da reflexão filosófica das descobertas antropológicas maiores e incontestáveis: o homem se humanizou fazendo o retorno para o mundo exterior, confrontando-se com a matéria, "exteriorizando" suas funções biológicas nas ferramentas e "exteriorizando" suas programações numa memória social. Os animais podem ter competências sociais muito elaboradas, basta citar o caso dos chimpanzés e dos bonobos. Contudo, o homem é sem dúvida o único vivente que multiplicou, enriqueceu e complicou as formas de sua organização social na medida mesma em que ele multiplicou, enriqueceu e complicou seus modos de confrontação à matéria. Há certamente técnica na animalidade, há mesmo mediações técnicas complicadas entre os animais (em todo caso em certas espécies animais que não somente utilizam ferramentas, mas que podem também combinar operações técnicas segundo uma "cadeia operatória" elaborada). Dito isto, o homem é esse vivente especial cujas formas de organização social podem sempre ser transformadas por irrupção de modos inéditos de confrontação com a matéria. É muito provavelmente uma situação desse tipo que nos expõem as biotecnologias e as nanotecnologias hoje: novas relações para com a matéria são experimentadas nos laboratórios, essa situação é suscetível de inquietar as formas sociais de humanidade atual. Simondon elevou a um alto nível de elaboração filosófica essa constatação, feita pelos paleoantropólogos, que a realidade e a evolução humana repousam sobre a existência de uma 
solidariedade entre modo de confrontação à matéria e modo de agrupamento. Em suma, entre técnica e sociedade. Essa solidariedade que faz a originalidade da fórmula humana no conjunto do mundo vivo desenha então os contornos disso que Simondon não hesita em denominar de um humanismo para o nosso tempo. Sociologia, tecnologia, humanismo: tais são os três pilares da filosofia da individuação humana proposta por Simondon.

\section{Referências Bibliográficas}

BERGSON, Henri. Matière et mémoire. Essai sur la relation du corps à l'esprit. Paris: PUF, 1965.

BERGSON, Henri. Les Deux sources de la morale et de la religion. Paris: PUF, 1982 [1932].

CANGUILHEM, Georges, «Le problème des régulations dans l'organisme et dans la société », in: Ecrits sur la médecine. Paris: Seuil, 2002.

FOUCAULT, Michel. Les Mots et les choses. Une archéologie des sciences bumaines. Paris: Gallimard, 1966.

KARSENTI, Bruno., La Société en personnes: études durkheimiennes. Paris: Economica, 2006.

LE BLANC, Gilhaume. L’Esprit des sciences humaines. Paris: Vrin, 2005.

LEROI-GOURHAN, André. Le Geste et la parole. Deus tomes, Paris: Albin Michel, 1964 et 1965.

MARCUSE, Herbert. L'bomme unidimensionnel. Essai sur l'idéologie de la société industrielle avancée. Paris: Editions de Minuit, 1968.

MAUSS, Marcel. «Les techniques du corps », in: Sociologie et anthropologie. Paris: PUF, 1950, p. 363-386.

MERLEAU-PONTY, Maurice. Merleau-Ponty à la Sorbonne. Résumés de cours, 1949-1952. Paris: Cynara, 1988.

Filosofia e Educação - ISSN 1984-9605

Volume 6, Número 3 - Outubro de 2014 
MOUTAUX, Jacques. «Sur la philosophie de la nature et la philosophie de la technique de Gilbert Simondon», in: BLOCH, Olivier (sous la dir.). Philosophies de la nature. Paris: Publications de la Sorbonne, 1994.

NAVILLE, Pierre. Vers l'automatisme socia? Problèmes du travail et de l'automation. Paris: Gallimard, 1963.

SIMONDON Gilbert. Sur la technique. Paris: PUF, 2014.

SIMONDON Gilbert. L'Individuation à la lumière des notions de forme et d'information. Grenoble: Jérôme Millon, 2005 [1964].

SIMONDON, Gilbert. Du mode d'existence des objets techniques. Paris: Aubier, 2012 [1958]. 